\title{
Spatial Effects of Lateral Deformations of Supporting Structure of Deep Excavation
}

\author{
C. L. Li ${ }^{1,2^{*}}$, Y. M. Feng ${ }^{3}$, F. Yang ${ }^{1}$ and P. Hagan ${ }^{4}$ \\ ${ }^{1}$ Institute of Urban Construction, Hebei Normal University of Science \& Technology, Qinhuangdao 066004, China \\ ${ }^{2}$ School of Civil Engineering and Mechanics, Yanshan University, Qinhuangdao 066004, China \\ ${ }^{3}$ Business department, Qinhuangdao Port Co., Lt., Qinhuangdao 066004, China \\ ${ }^{4}$ School of Mining Engineering, University of New South Walse, Sydney 2052, Australia
}

Received 2 March 2015; Accepted 23 September 2015

\begin{abstract}
In order to improve the design theories of the supporting structure, based on a deep excavation project, FLAC ${ }^{3 \mathrm{D}}$ was used to simulate the spatial effects of the lateral deformation happened in the process of the deep excavation for the diaphragm wall. The results showed that there would produce the spatial effects in both the horizontal and depth directions; the spatial effects of the lateral deformations were different for the long and short sides; and the spatial effects of the lateral deformation were only obvious in a certain distance from the bottom to the top of the deep excavation. The nonuniformity coefficients of the lateral deformations were modified, and according to the supporting forms and supporting parameters this study provided some theory basis for the supporting design of the deep excavation.
\end{abstract}

Keywords: Deep Excavation, Underground Diaphragm Wall, Lateral Deformation, Spatial Effect, Non-uniformity Coefficient

\section{Introduction}

The deep excavation is normally a three-dimension spatial structure including of length, width and depth. During the design process of supporting forms and parameters of the deep excavation, the influences of spatial effects are usually neglected and it is considered as a plane problem to study, which is satisfied with the plane strain hypothesis. Although the spatial effects of the deep excavation in the direction of its depth are considered in some designs, the strong supporting function in horizontal directions of the diaphragm wall at the ends of the excavation cannot be taken into consideration. So, it is a relatively safe method to design the supporting system. With the rapid development of civil construction, many deep excavation projects emerged in secession. Its characteristics such as high danger, individuality and locality, mean more and tougher technical challenges to the supporting and construction of the deep excavation. There are many instabilities, collapses and water flush accidents, especially in some soft soil areas in recent years [1], [2]. So the deformation happened in the construction process of deep excavation is always a hard and hot issue, related to the supporting design and construction safety.

These years, a lot of studies related to the deformation happened in the construction process of the deep excavation have been done by Chinese and foreign scholars. For example, $\mathrm{Xu}$ et al. gathered the data about the measured deformations of 93 deep excavations in Shanghai, in which the underground diagram walls are taken as space supporting structures, to study the deformation characters of the

* E-mail address: Iclcc_010@163.com ISSN: 1791-2377 @ 2015 Kavala Institute of Technology. All riahte recerved underground diagram walls from the viewpoint of statistics [3]. Lei et al. proposed the simplified calculation of spatial effects in cohesive soils when the large-long-deep foundation pit was in tension crack-shear and pure shear failure modes, and put forward the corresponding formulas of spatial effects coefficient, and also analyzed two examples [4]. Li et al. took a deep excavation project in Beijing as the research object, used finite element software to simulate the construction process of deep excavation and then compared and analyzed the simulation and measured results. The effects of the size of the deep excavation, the depth of embedded pile and construction state to the deformation of the deep excavation have been studied [5]. Li et al. utilized MIDAS/GTS to simulate the supporting structure of a railway station in Xian and the surface around it and then, calculate the displacements. It has been found that the simulation results are nearly the same with the measured results and that the displacements using layered excavation method are bigger than the ones using step excavation method, which means the latter method is able to effectively control the space geometry of a deep excavation and reduces the displacements of the soil and the supporting structure [6]. Li et al. analyzed a database of 30 case histories of field monitoring on Beijing subway stations and compared the results with worldwide case histories, the result shows that foundation pit deformation has obvious temporal and spatial effects [7]. Li et al. took Neijiang Station of Shanghai Metro Line 12 as an example and elaborated the scheme of the load-structure model of the composite wall system, the design of the internal support system combined reinforced concrete with steel tube by using finite element software SAP84 [8]. Liao et al. took large-scale deep excavation of radio and television station in Suzhou modern media plaza as engineering background, collecting the measured data of 11 square pits using bored 
pile retaining structure and normal construction method and at least 23 elongated subway foundation using of underground diaphragm wall of retaining structure in the region, and comparatively analyzed the deformation behavior of large-scale comprehensive deep pits with different retaining structures, different shapes in the Suzhou region [9].

For foreign scholars, Finno et al. measured the threedimensional ground deformations during construction of a deep tied-back excavation in Chicago and presented an empirical approach to estimate the distribution of ground movements parallel to a supported wall [10]. Hsieh et al. used a three-dimensional numerical method to obtain the influencing factors of the maximum wall deflections and demonstrated the effectiveness of cross walls in reducing lateral wall deflections [11]. Hung et al. conducted the finite element simulations of two deep excavations in soft cohesive soils involving collapse and illustrated the insignificant difference between the associative and nonassociative versions of enhanced bounding surface model [12]. Zahmatkesh et al. carried out a drained analysis using Drucker-Prager multisurface kinematic plasticity model for sand and calculated the ground surface settlement and wall deflection for the various conditions of excavation [13].

Overall, although a lot of research has been done by these experts, the deformation and instability of a deep excavation still deserve further research, because most of the researches are aimed to a given project. Taking the deep excavation of Huangmugang subway station in Shenzhen for example, based on the three-dimension calculation model of the deep excavation, the whole process of excavation was simulated, the characteristics of spatial effects of lateral deformation in the depth direction and the horizontal directions of the long and short sides were analyzed and the non-uniformity coefficients of lateral deformation in the full depth by spline interpolation method were calculated, and this study is to provide a reference for the support design and construction of the deep excavation.

\section{Enginering background}

\subsection{Project overview}

Huangmugang station of Shenzhen metro line 7 in China is a three-layer island platform station. The open cut method has been adopted and the total length is $200 \mathrm{~m}$. The depth of the standard section of main body of the supporting structure for the railway station is about $26 \mathrm{~m}$ and its width is about $20 \mathrm{~m}$.

\subsection{Engineering geology and hydrology}

After investigating the construction site, we found that the soils could be divided into 6 layers, according to its genetic type, soil structure and characters. The depth and physical parameters of each layer are shown in Table 1 . The underground water is mainly composed of pore water and bedrock fissured water. The pore water is mainly in the alluvial cohesive soil, debris cohesive soil and completely decomposed granite. The main discharge means are evaporation and run-off and the main supply source is atmospheric precipitation.

\subsection{Design of the supporting structure}

The $800 \mathrm{~mm}$ thickness underground diaphragm wall is chosen as the supporting structure. Within the embedded depth of the diaphragm wall, which is $6 \mathrm{~m}$ under the designed depth of the deep excavation, the soil properties are excellent. Considering the underground water is mainly in the upper plain fill, the water can be drained, which means its influence to the deep excavation is relatively small. There are six layers of internal supports in the deep excavation and the vertical distances between each layer are 1, 6, 5, 5, 3, and $3 \mathrm{~m}$. The horizontal distance between concrete bracings is 6 $\mathrm{m}$ and it is $3 \mathrm{~m}$ for steel bracings. The support forms of the support and bolting system are diagonal supports, corner supports and fringe truss supports.

\section{The computational model}

\subsection{Building the model}

The three-dimension numerical model of the deep excavation was built by using ANSYS and FLAC ${ }^{3 \mathrm{D}}$ as shown in Figure 1. The stratification of soil, excavation condition and the contact surface between the supporting wall and soil were considered in the model. Its plan sizes are $200 \mathrm{~m} \times 20 \mathrm{~m}$. To reduce the calculation time and considering its symmetry, $1 / 4$ model was taken to calculate.

The length of the model in $Y$-axis direction was 10 times of its width and the length of the model in $X$-axis direction was 2 times of its length. The length of the model in $Z$-axis direction was 4 times of its depth. The final sizes of the three-dimension model were $200 \mathrm{~m} \times 110 \mathrm{~m} \times 112 \mathrm{~m}$, as shown in Figure 1.

Tab. 1. Physical and mechanical parameters of the soil of the pit

\begin{tabular}{|c|c|c|c|c|c|c|}
\hline Number of layer & $\begin{array}{l}\text { Thickness } \\
\text { (m) }\end{array}$ & $\begin{array}{l}\text { Density } \\
\left(\mathrm{kN} / \mathrm{m}^{3}\right)\end{array}$ & $\begin{array}{l}\text { Friction angle } \\
\left({ }^{\circ}\right)\end{array}$ & $\begin{array}{l}\text { Cohesion } \\
(\mathrm{kPa})\end{array}$ & $\begin{array}{l}\text { Bulk modulus } \\
(\mathrm{MPa})\end{array}$ & $\begin{array}{l}\text { Shear modulus } \\
(\mathrm{MPa})\end{array}$ \\
\hline (1) Plain bankette & 3 & 18.00 & 12 & 13 & 3.33 & 1.11 \\
\hline (2) Medium sand & 1 & 19.80 & 18 & 20 & 7.41 & 3.03 \\
\hline (3) Gravelly sand & 14 & 17.70 & 27 & 30 & 12.50 & 5.77 \\
\hline (4) Strong weathered rock & 4 & 18.30 & 30 & 42 & 59.20 & 27.30 \\
\hline (5) The weathered rock & 14 & 25.00 & 35 & 600 & 606.00 & 313.00 \\
\hline (6) Slightly weathered rock & 76 & 25.50 & 42 & 4000 & 5560.00 & 4170.00 \\
\hline
\end{tabular}




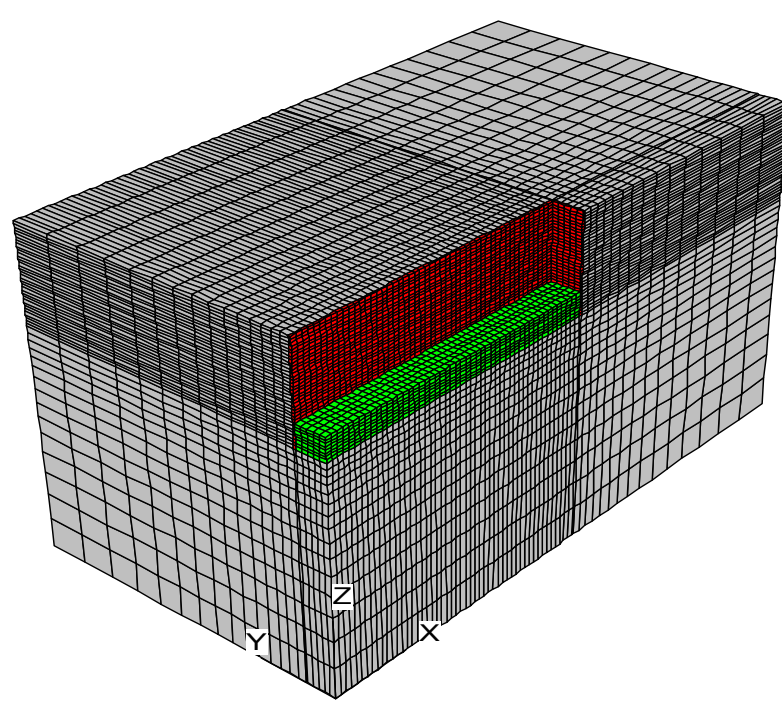

Fig.1. The computational model

At these surfaces of $x=200 \mathrm{~m}, y=110 \mathrm{~m}$ and $z=0 \mathrm{~m}$, only the normal freedoms were restrained. Where $z=112 \mathrm{~m}$ was the earth's surface. Because man-made symmetrical cut surface was used as the boundary surface, an initial condition was set to make the model get initial stresses at initial stage. The lateral pressure coefficient was set as 0.5 , every soil element was set as a brick with 8 nodes and 6 surfaces and the excavation process was fulfilled through null model. The strength of the soil is assumed to be satisfied with Mohr-Coulomb criterion.

\subsection{Support parameters}

The diaphragm wall element was also set as a brick with 8 nodes and 6 surfaces and the element of the lateral bracings was simulated using beam element. Considering there were small cracks in working condition, the stiffness of C30 concrete had been multiplied by 0.85 . There were two diaphragm walls at the edges of the deep excavation, $X=100.0-100.8 \mathrm{~m}$ and $Y=10.0-10.8 \mathrm{~m}$. The first ones of the six layers bracings were $1.0 \mathrm{~m} \times 0.8 \mathrm{~m}$ steel reinforced concrete bracings and the other layers were $\Phi 609 \mathrm{~mm} \times 16$ mm steel pipe bracings (Q235). The pre-applied axial force of a steel bracing was set as $60 \%$ of the initial calculation axial force. The supporting structure was shown in Figure 2.

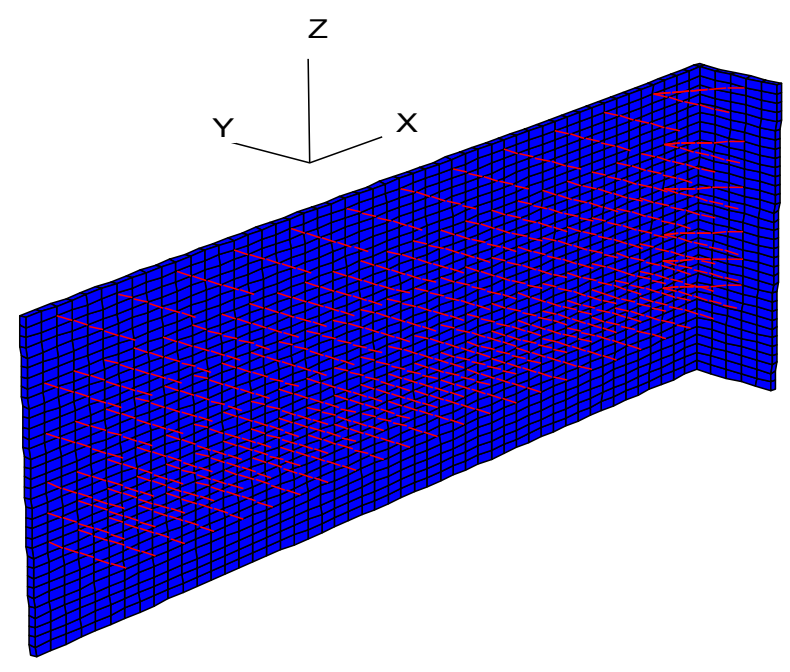

Fig.2. Supporting structure

\subsection{Contact condition description}

To reflect the lateral deformations of the diaphragm wall in the calculation process, the contact condition between the soil and the diaphragm wall had to be considered. In this model, the contacts between the diaphragm wall and the soil underneath, in and out of the deep excavation had been set up. The contact parameters were shown in Table 2. The whole excavation process was divided into seven excavation conditions and one initial balance condition, as shown in Table 3.

Tab. 2. The contact parameters between the diaphragm wall and the soil

\begin{tabular}{llllll}
\hline Item & $K n(\mathrm{GPa})$ & $K s(\mathrm{GPa})$ & Ten. $(\mathrm{MPa})$ & Coh. $(\mathrm{MPa})$ & Fri. $\left(^{\circ}\right)$ \\
\hline Value & 24.0 & 24.0 & 0.0 & 0.0 & 14.0 \\
\hline
\end{tabular}

Tab. 3. Simulation steps of pit excavation process

\begin{tabular}{ll}
\hline Conditions & Contents of Simulation \\
\hline Excav 0 & $\begin{array}{l}\text { Initial balance calculation including diaphragm wall } \\
\text { Excavate to } 1.5 \mathrm{~m} \text {, construct the first transverse } \\
\text { bracing at } 1 \mathrm{~m} \text { depth }\end{array}$ \\
Excav 1 & $\begin{array}{l}\text { Excavate to } 7.5 \mathrm{~m} \text {, construct the second transverse } \\
\text { bracing at } 7 \mathrm{~m} \text { depth }\end{array}$ \\
Excav 3 & $\begin{array}{l}\text { Excavate to } 12.5 \mathrm{~m} \text {, construct the third transverse } \\
\text { bracing at } 12 \mathrm{~m} \mathrm{depth}\end{array}$ \\
Excav 4 & $\begin{array}{l}\text { Excavate to } 17.5 \mathrm{~m} \text {, construct the fourth transverse } \\
\text { bracing at } 17 \mathrm{~m} \mathrm{depth}\end{array}$ \\
Excav 5 & $\begin{array}{l}\text { Excavate to } 20.5 \mathrm{~m} \text {, construct the fifth transverse } \\
\text { bracing at } 20 \mathrm{~m} \mathrm{depth}\end{array}$ \\
Excav 6 & $\begin{array}{l}\text { Excavate to } 23.5 \mathrm{~m} \text {, construct the sixth transverse } \\
\text { bracing at } 23 \mathrm{~m} \text { depth }\end{array}$ \\
Excav 7 & Excavate to $26 \mathrm{~m}$ (the bottom of the pit)
\end{tabular}

\section{Calculation results and lateral deformations analysis}

\subsection{Analysis of lateral deformation trend}

Figures 3 and 4 were respectively the deformation contours of $y$-direction and $x$-direction of an overall model at excav 7 stage. Combining with the two figures it could be seen, the $\mathrm{x}$-direction and $\mathrm{y}$-direction displacements of the model were mainly concentrated in the soil area behind the diaphragm wall, the displacement away from the wall area was small.

Figures 5 and 6 were respectively the deformation contours of the $\mathrm{y}$-direction and $\mathrm{x}$-direction of the diaphragm wall at 1,000 magnification at excav 7 stage. From Figure 5 it could be seen apparently that the nonuniform deformations of long side of the diaphragm wall occurred, the middle part of diaphragm wall had a greater tendency to swell toward the pit, and this trend was weak in the two ends of pit, the results came from the strengthening effect of corner stiffness of the pit, which could effectively limit the lateral deformations of the diaphragm wall in the pit corners, the maximum lateral deformation was negative $8.63 \mathrm{~mm}$. Similarly, from Figure 6 it could be seen that the short side of diaphragm wall had a similar deformation trend, the spatial effect of lateral deformation was significant, the maximum lateral deformation was negative $4.08 \mathrm{~mm}$.

\subsection{Spatial effects analysis of lateral deformations}

The above content was a simple qualitative description about the spatial effects of lateral deformation of the diaphragm wall. In fact, it is more valuable about the scope of the 
uneven distribution of lateral deformations, the difference of the distribution between long and short sides, as well as the influencing factors to the spatial effect.

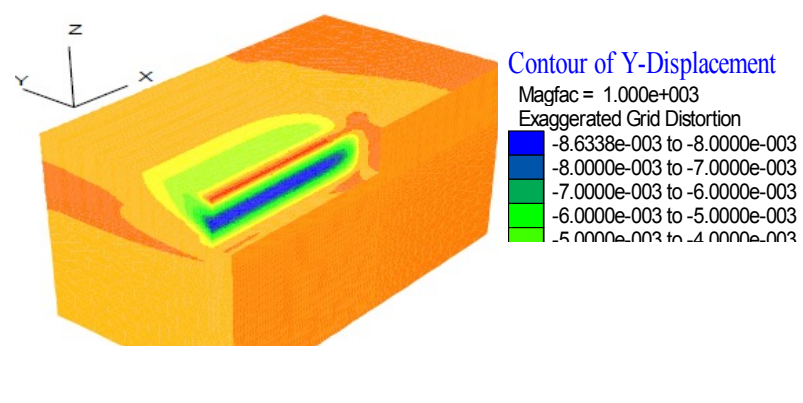

Fig.3. $Y$-direction deformation of the whole pit

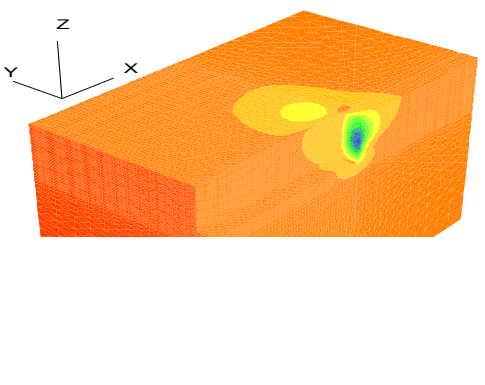

Contour of X-Displacement Magfac $=2.000 \mathrm{e}+003$ Exaggerated Grid Distortion $-4.0790 \mathrm{e}-003$ to $-4.0000 \mathrm{e}-003$ $-4.0000 \mathrm{e}-003$ to $-3.5000 \mathrm{e}-003$ $-3.5000 \mathrm{e}-003$ to $-3.0000 \mathrm{e}-003$ $-3.0000 \mathrm{e}-003$ to $-2.5000 \mathrm{e}-003$ $-2.5000 \mathrm{e}-003$ to $-2.0000 \mathrm{e}-003$ $-2.0000 \mathrm{e}-003$ to $-1.5000 \mathrm{e}-003$ $-1.5000 \mathrm{e}-003$ to $-1.0000 \mathrm{e}-003$ $-1.0000 \mathrm{e}-003$ to $-5.0000 \mathrm{e}-004$ $-5.0000 \mathrm{e}-004$ to $-4.8753 \mathrm{e}-004$

Fig.4. $X$-direction deformation of the whole pit

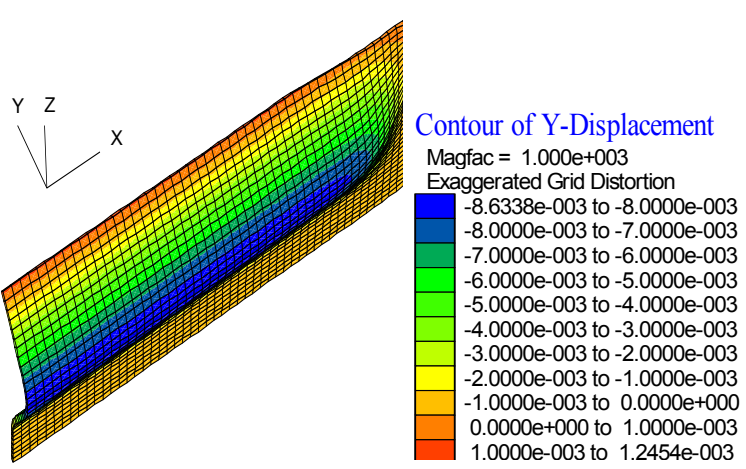

Fig.5. $Y$-direction deformations of diaphragm wall

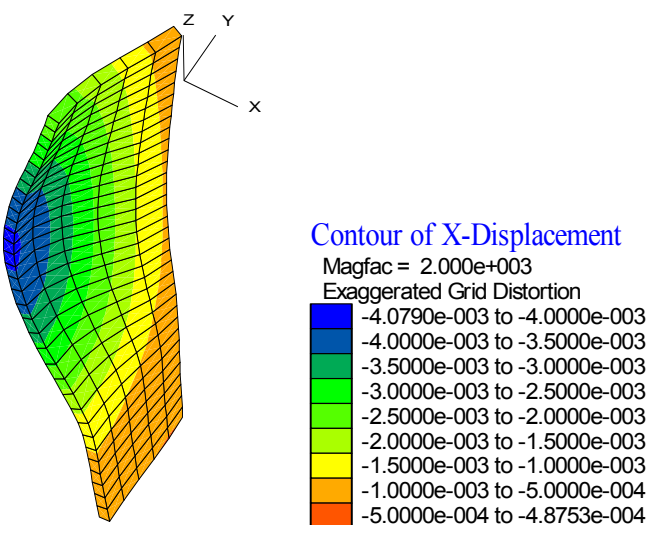

Fig.6. $X$-direction deformations of diaphragm wall

\subsubsection{Spatial effects of lateral deformation in the depth direction}

The variations of the lateral deformation of the long side midpoint $(x=0)$ and the short side midpoint $(y=0)$ of the diaphragm wall in the different excavation stages were shown in Figures 7 and 8, respectively.

\section{$1 \quad 0 \quad \begin{array}{cccccc}\text { Lateral displacement } / \mathrm{mm} \\ -2\end{array}$}

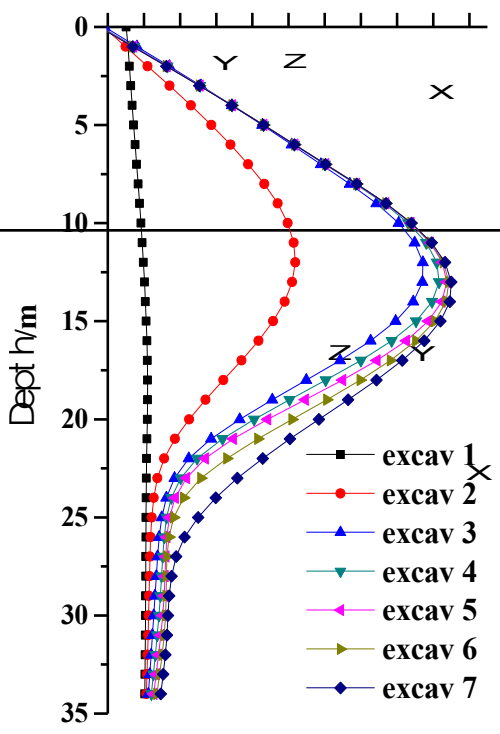

Fig.7. Lateral deformations of long side midpoint

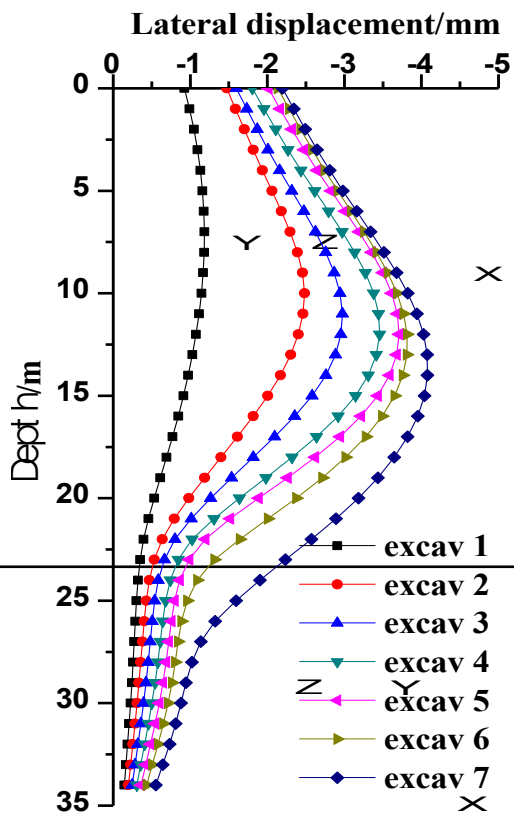

Fig.8. Lateral deformations of short side midpoint

The spatial effect of lateral deformation of the pit in the depth direction was obvious. It could be seen that the lateral deformations of the pit diaphragm wall in the first three excavation stages grew fastest, and after that they stabilized. Due to the embedded effect of slightly weathered rock underlying, the lateral deformations of the lower part wall were small. The deformation forms of diaphragm wall gradually changed from the approximate line to the parabola line, the point corresponding to the maximum lateral deformation of diaphragm wall was the parabola vertex and the vertex continued downward with the excavation, and in excav 7 stage the midpoints of the long side and the short side of the pit both reached the maximum. In addition, the lateral deformation behavior of the long side and the short side in the same excavation stage also displayed some differences. Taken the stage of excav 2 as an example, the 
maximum lateral deformation of the long sidewall was negative $4.19 \mathrm{~mm}$, and that of the short sidewall only was negative $2.5 \mathrm{~mm}$. It was found that the excavation length, depth and excavation conditions would affect the spatial effects of lateral deformation in the depth direction.

\subsubsection{Spacial effects of lateral deformation in the horizontal direction}

Figures 9 and 10 were the lateral deformation curves of long and short sides of diaphragm wall in their whole length when in the condition of excav 7 , respectively. It could be seen from Figure 9 that these curve had the common characteristics, and they first maintained the approximate line for the segment length in the central part of pit, and then converted into a curve in the ends of pit, However, in Figure 10 , addition to a small area of central part, each figure was basically in curve line state, which indicated that there was a difference of deformation law between long and short sides, and the lateral deformation of diaphragm walls of pit in long side direction even more closed to the plane strain assumption. In Figure 9, simultaneously taking $1.0 \mathrm{~m}$ depth and $15 \mathrm{~m}$ depth curves for example, the $1.0 \mathrm{~m}$ depth curve maintained the straight section for about $80 \mathrm{~m}$, and the $15 \mathrm{~m}$ depth curve maintained the straight section for about $65 \mathrm{~m}$. Thus, the side length of pit and a diaphragm wall depth would have an impact on the spatial effects of lateral deformations in the horizontal direction.

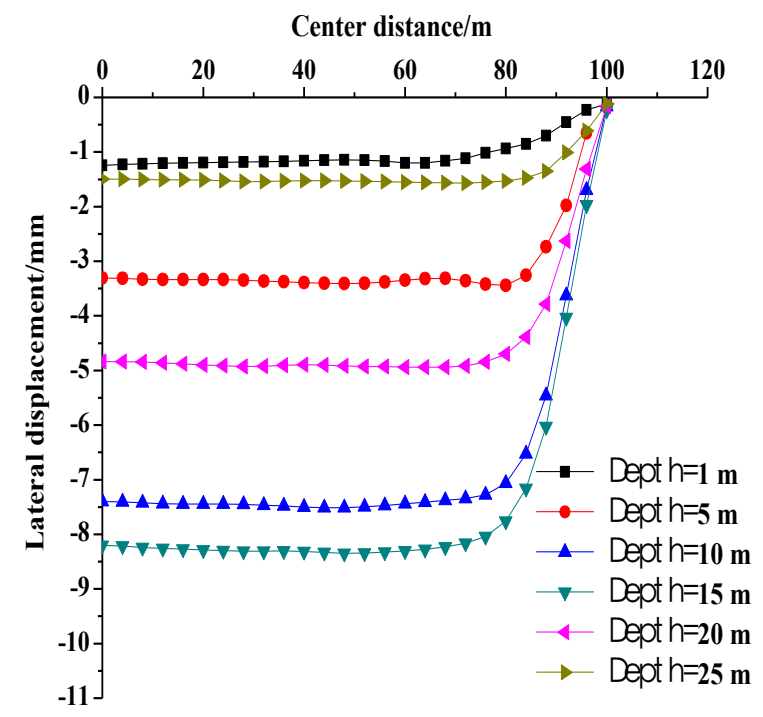

Fig.9. Lateral deformations of long side in whole length

\subsection{Analysis of non-uniformity coefficient}

\subsubsection{Definition of non-uniformity coefficient}

In order to make a description of the scope of spatial effects, the non-uniformity coefficient $k$ of lateral deformations is defined as the ratio of curve segment length of the diaphragm wall and the total length of it, where the total length is the length of $1 / 4$ model, and it can reflect the spatial effect degree of lateral deformations at a certain depth. It is easily known that the larger the $k$ value is, the greater the spatial effect ranges are.

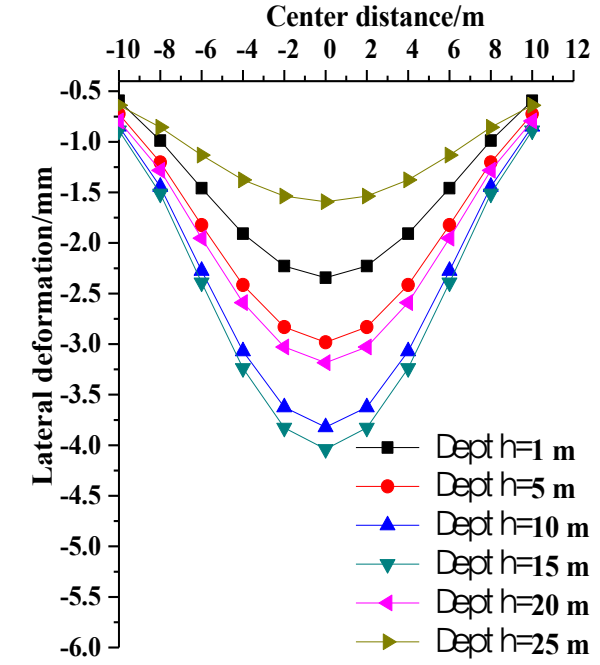

Fig.10. Lateral deformations of long side in the whole length

$$
k=l_{s} / l
$$

Where $l_{s}=$ the curve segment length of the deformation curve; $l=$ the total length of the diaphragm wall.

The values of $k$ of long and short sides got by calculating the curve length from Figures 9 and 10 were showed in Figure 11.

Figure 11 was correlation curves of long and short sides between the non-uniformity coefficient and the pit depth. As could be seen from Figure 11, the $k$ values at different depths of long side was smaller than that of the short side, for the same depth, the spatial effects of long side concentrated in the ends of pit, and for the short side there was basically a spatial effect in the entire length. In addition, from the viewpoint of the variation in the depth direction of pit, the $k$ value of two curves both first increased and then decreased with depth, combined with the analysis of Figures 7 and 8, the spatial effect of depth direction mainly concentrated in the scope of $10-20 \mathrm{~m}$, that was within the scope of about $50 \%$ of that depth. Therefore, the internal support should be properly strengthened within this depth scope.

\subsubsection{Cubic spline interpolation}

Since Figure 11 only represents the $k$ value at the portion depths, for other locations, such as each crossbars, the top and bottom position of pit, each floor corresponding to the main structure, etc., the size of the $k$ value also need to be known.

Thus, the non-uniformity coefficients of pit in the full depth range could be calculated, and according this the deformation curve segment (spatial effect area) length is 100 $\times k(h)$ by anti reasoning. For example, at the fourth crossbars of $h=17.5 \mathrm{~m}$, bringing $h$ into $k(h), k(17.5)=$ 0.413 could be calculated, by the anti reasoning the deformation curve length at both ends of the pit is $100 \times$ $0.413=41.3 \mathrm{~m}$, i.e. in the fourth crossbars position, the support form and parameters of pit within the range of 41.3 $\mathrm{m}$ in both ends are necessarily adjusted to accommodate better lateral deformations. Similarly, the length of the influence area at the top of pit, bottom, rigid joints and at the other rungs could also be calculated, which could provide a reference for the supporting structure design according to this calculation. 


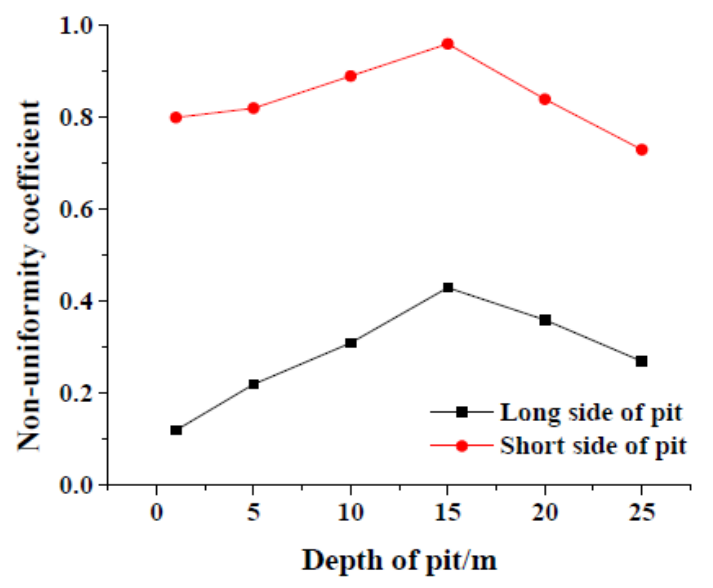

Fig.11. Variation curves of non-uniformity coefficient

$$
k(h)=\left\{\begin{array}{cc}
-0.00585 \times \frac{(h-1)^{3}}{6 \times 4}+0.1 \times \frac{(5-h)}{4}+ & \\
\left(0.22-\frac{-0.00585}{6} \times 4^{2}\right) \frac{(h-1)}{4}, & \\
-0.00585 \times \frac{(10-h)^{3}}{6 \times 5}+0.00667 \times \frac{(h-5)^{3}}{6 \times 5}+ & \\
\left(0.22-\frac{-0.00585}{6} \times 5^{2}\right) \frac{(10-h)}{5}+ & \\
\left(0.31-\frac{0.00667}{6} \times 5^{2}\right) \frac{(h-5)}{5}, & \\
0.00667 \times \frac{(15-h)^{3}}{6 \times 5}+(-0.01362) \times \frac{(h-10)^{3}}{6 \times 5}+ & \\
\left(0.31-\frac{0.00667}{6} \times 5^{2}\right) \frac{(15-h)}{5}+ & \\
\left(0.43-\frac{-0.01362}{6} \times 5^{2}\right) \frac{(h-10)}{5}, & h \in[10,15] \\
-0.01362 \times \frac{(20-h)^{3}}{6 \times 5}+0.0022 \times \frac{(h-15)^{3}}{6 \times 5}+ & \\
\left(0.43-\frac{-0.01362}{6} \times 5^{2}\right) \frac{(20-h)}{5}+ & \\
\left(0.36-\frac{0.0022}{6} \times 5^{2}\right) \frac{(h-15)}{5}, & \\
\left(0.36-\frac{0.0022}{6} \times 5^{2}\right) \frac{(25-h)}{5}, & \\
0.0022 \times \frac{(25-h)^{3}}{6 \times 5}+0.27 \times \frac{(h-20)}{5}+ & h \in[15,20]
\end{array}\right.
$$

\section{Conclusions}

By ANSYS and FLAC ${ }^{3 \mathrm{D}}$, the three-dimension simulation can effectively reflect the lateral deformation law of the diaphragm wall in the excavation process. There are spatial effects in both horizontal and depth directions for lateral deformation and the spatial effects of long and short sides are different.

The spatial effect of the lateral deformation will not affect all the zones of the diaphragm wall, but only in certain distances from the bottom and top of it. So, it is recommended that lateral deformation monitoring should not only be concentrated on the magnitude of the deformation. It is also important to point out the deformation positions, so that the design of supporting parameters and structures can be more effective.

From the viewpoint of maintaining the stability of the deep excavation, adopting the same supporting parameter along the edge of the deep excavation is not appropriate. It is recommended that, in the process of designing the supporting system of a deep excavation, the spline interpolation method can be used to calculate the nonuniformity coefficient $\mathrm{k}$ in different positions and then the length of the influence area at two ends of the deep excavation can be got. If the length of the influence area is smaller compared with the total length of the diaphragm wall, a single supporting parameter can be adopted. Otherwise, it is recommended that the supporting forms and parameters near the bottom of the deep excavation should be designed specially.

\section{Acknowledgements}

This work was financially supported by the National Natural Science Foundation of China (51474188; 51474097; 51074140), the Natural Science Foundation of Hebei Province of China (E2014203012), 2015 Endeavor Research Fellowship and Program for Taihang Scholars. All these are gratefully acknowledged.

\section{References}

1. Huang, M. S., Wang, W. D., and Zheng, G., "A Review of Recent Advances in the underground and deep excavations", China Civil Engineering Journal, 45(6), 2012, pp.146-155.

2. Xue, L. Y., Yang, W. S., and Li, R. N., "Discussion and analysis of accident reasons of deep foundation pits", Chinese Journal of Geotechnical Engineering, 35( $\left.\mathrm{S}_{1}\right), 2013$, pp. 468-473.

3. Xu, Z. H., Wang, J. H., and Wang, W. D., "Deformation behavior of diaphragm walls in deep excavations in Shanghai", China Civil Engineering Journal, 41(8), 2008, pp. 81-86.

4. Lei, M. F., Peng, L. M., and Shi, C. H., An, Y. L., "Research on construction spatial effects in large-long-deep foundation pit", Rock and Soil Mechanics, 31(5), 2010, pp. 1579-1584.

5. Li, S. W., Gao, H. D., and Yang, T. D., "Monitoring and numerical analysis of a deep foundation pit", Chinese Journal of Geotechnical Engineering, 33( $\left.\mathrm{S}_{1}\right), 2011$, pp. 284-291.
6. Li, H., Yang, L. S., and Li, Z., Zhu, W. J., and Cui, P. F., "Research on construction spatial effects in a deep foundation pit of Metro station based on MIDAS/GTS", Railway Engineering, 4, 2011, pp. 83-89.

7. Li, S., Zhang, D. L., and Fang, Q., Lu, W., "Research on characteristics of ground surface deformation during deep excavation in Beijing subway", Chinese Journal of Rock Mechanics and Engineering, 31(1), 2012, pp. 189-198.

8. Li, S. G., and Liu, Z. X., "Structure Design for Foundation Excavation Supporting of Neijianglu Station of Shanghai Metro", Railway Standard Design, 1, 2013, pp. 101-104.

9. Liao, S. M., Wei, S. F., and Tan, Y., Liu, J. X., "Field performance of large-scale deep excavations in Suzhou", Chinese Journal of Geotechnical Engineering, 37(3), 2015, pp. 458-469.

10. Finno, R. and Roboski, J., "Three-Dimensional Responses of a Tied-Back Excavation through Clay", Journal of Geotechnical and Geoenvironmental Engineering, 131(3), 2005, pp. 273-282. 
C. L. Li , Y. M. Feng, F. Yang and P. Hagan/Journal of Engineering Science and Technology Review 8 (3) (2015) $71-77$

11. Hsieh, P. G., Ou, C. Y., and Lin, Y. L., "Three-dimensional numerical analysis of deep excavations with cross walls", Acta Geotechnica, 8(1), 2013, pp. 33-48.

12. Hung, C., Ling, H. I., and Kaliakin, V. N., "Finite Element Simulation of Deep Excavation Failures", Transp. Infrastruct. Geotech, 1, 2014, pp. 326-345.
13. Zahmatkesh, A., Choobbasti, A. J., "Evaluation of wall deflections and ground surface settlements in deep excavations", Arabian Journal of Geosciences, 8(5), 2015, pp. 3055-3063. 